\title{
Lifestyle in Undergraduate Students and Demographically Matched Controls during the COVID-19 Pandemic in Spain
}

\author{
María Giner-Murillo ${ }^{1,+}+\mathbb{C}$, Beatriz Atienza-Carbonell ${ }^{1,+} \oplus^{\infty}$, Jose Cervera-Martínez ${ }^{1,2,+} \oplus$, \\ Teresa Bobes-Bascarán ${ }^{3,4,5}{ }^{(\mathbb{D}}$, Benedicto Crespo-Facorro ${ }^{3,6,7}$, Raquel B. De Boni ${ }^{8}{ }^{\circ}$, Cristina Esteban ${ }^{6}{ }^{\circ}$, \\ María Paz García-Portilla ${ }^{3,4,9}$ (), Susana Gomes-da-Costa ${ }^{10}$, Ana González-Pinto ${ }^{3,11}$, María José Jaén-Moreno ${ }^{12,13}$,

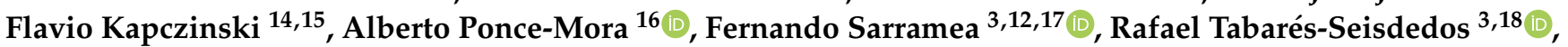

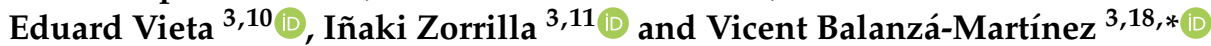

1 Department of Medicine, University of Valencia, 46010 Valencia, Spain; magimu912@gmail.com (M.G.-M.); beatrizatica@gmail.com (B.A.-C.); joecerve@hotmail.com (J.C.-M.)

2 Hospital de Denia-Marina Salud, 03700 Alicante, Spain

3 Centro de Investigación Biomédica en Red de Salud Mental (CIBERSAM), 28007 Madrid, Spain; mtbobes@gmail.com (T.B.-B.); benedicto.crespo.sspa@juntadeandalucia.es (B.C.-F.); albert@uniovi.es (M.P.G.-P.); anapinto@telefonica.net (A.G.-P.); fscferro69@gmail.com (F.S.); rafael.tabares@uv.es (R.T.-S.); EVIETA@clinic.cat (E.V.); i.zorrilla@gmail.com (I.Z.)

check for updates

Citation: Giner-Murillo, M.;

Atienza-Carbonell, B.

Cervera-Martínez, J.; Bobes-Bascarán, T.; Crespo-Facorro, B.; De Boni, R.B.; Esteban, C.; García-Portilla, M.P.; Gomes-da-Costa, S.; González-Pinto, A.; et al. Lifestyle in Undergraduate Students and Demographically Matched Controls during the COVID-19 Pandemic in Spain. Int. J. Environ. Res. Public Health 2021, 18, 8133. https://doi.org/10.3390/ ijerph18158133

Academic Editor: Sharon Lawn

Received: 6 June 2021

Accepted: 26 July 2021

Published: 31 July 2021

Publisher's Note: MDPI stays neutral with regard to jurisdictional claims in published maps and institutional affiliations.

Copyright: (C) 2021 by the authors. Licensee MDPI, Basel, Switzerland This article is an open access article distributed under the terms and conditions of the Creative Commons Attribution (CC BY) license (https:// creativecommons.org/licenses/by/ $4.0 /)$
4 Servicio de Salud del Principado de Asturias (SESPA), Instituto de Investigación Sanitaria del Principado de Asturias (ISPA), 33011 Oviedo, Spain

5 Department of Psychology, University of Oviedo, 33003 Oviedo, Spain

6 Hospital Universitario Virgen del Rocío, IBIS, 41013 Seville, Spain; cristina.esteban.sspa@juntadeandalucia.es

7 Department of Psychiatry, Faculty of Medicine, University of Sevilla, 41004 Seville, Spain

8 Institute of Scientific and Technological Communication and Information in Health (ICICT), Oswaldo Cruz Foundation (FIOCRUZ), Rio de Janeiro 21040-360, Brazil; raqueldeboni@gmail.com

9 Department of Psychiatry, School of Medicine, University of Oviedo, 33003 Oviedo, Spain

10 Hospital Clinic, Institute of Neuroscience, University of Barcelona, IDIBAPS, Barcelona, 08036 Catalonia, Spain; GOMES@clinic.cat

11 Hospital Universitario de Alava, BIOARABA, UPV-EHU, 01005 Vitoria, Spain

12 Instituto Maimónides de Investigación Biomédica de Córdoba (IMIBIC), 14004 Córdoba, Spain; mjjaen@uco.es

13 Departamento de Ciencias Morfológicas y Sociosanitarias, Universidad de Córdoba, 14071 Córdoba, Spain

14 Department of Psychiatry and Behavioural Neurosciences, McMaster University, Mood Disorders Program, St. Joseph's Healthcare Hamilton, Hamilton, ON L8S 4L8, Canada; flavio.kapczinski@gmail.com

15 Department of Psychiatry, Universidade Federal do Rio Grande do Sul (UFRGS), Instituto Nacional de Ciência e Tecnologia Translacional em Medicina (INCT-TM), Porto Alegre 90040-060, Brazil

16 CMT-Motores Térmicos, Universitat Politècnica de València, 46002 Valencia, Spain; alponmo@mot.upv.es

17 Hospital Universitario Reina Sofía, Universidad de Córdoba, 14004 Córdoba, Spain

18 Teaching Unit of Psychiatry and Psychological Medicine, Department of Medicine, University of Valencia, 46010 Valencia, Spain

* Correspondence: vicente.balanza@uv.es; Tel.: +34-963983349

$+\quad$ These authors contributed equally to this work.

Abstract: Few studies have used a multidimensional approach to describe lifestyle changes among undergraduate students during the COVID-19 pandemic or have included controls. This study aimed to evaluate lifestyle behaviors and mental health of undergraduate students and compare them with an age and sex-matched control group. A cross-sectional web survey using snowball sampling was conducted several months after the beginning of COVID-19 pandemic in Spain. A sample of 221 students was recruited. The main outcome was the total SMILE-C score. Students showed a better SMILE-C score than controls $(79.8 \pm 8.1$ vs. $77.2 \pm 8.3 ; p<0.001)$, although these differences disappeared after controlling for covariates. While groups did not differ in the screenings of depression and alcohol abuse, students reported lower rates of anxiety ( $28.5 \%$ vs. $37.1 \% ; p=0.042)$. A lower number of cohabitants, poorer self-perceived health and positive screening for depression and anxiety, or for depression only were independently associated $(p<0.05)$ with unhealthier lifestyles in both groups. History of mental illness and financial difficulties were predictors of unhealthier lifestyles for students, whereas totally/moderate changes in substance abuse and stress management $(p<0.05)$ were predictors for the members of the control group. Several months after the pandemic, undergraduate students and other young adults had similar lifestyles. 
Keywords: lifestyle; undergraduate students; mental health; pandemic; COVID-19

\section{Introduction}

The 2019 coronavirus disease (COVID-19) pandemic is causing an unprecedented global crisis with respect to health and social factors. The pandemic and the measures adopted to combat it have had a substantial impact on the lifestyle habits of people worldwide [1,2].

Lifestyle is currently considered as a multidimensional construct encompassing a set of personal behaviors such as diet/nutrition, substance use, physical activity/exercise, stress management, restorative sleep, social support, and environmental exposures such as screen time and exposure to nature [3]. Healthy lifestyle habits have been consistently shown to influence individuals' physical health, mental health, and well-being [4-6].

An individual's lifestyle develops throughout life, but late adolescence and early youth are relevant stages in acquiring healthy lifestyle habits. Conversely, this is also a vulnerable period for substance misuse and worsened diet quality, especially when exercise is no longer linked to academic activities. Other notable changes are the increase in the use of screens, the existence of feelings of loneliness and social isolation, and sleep disturbances caused by maturational and psychosocial changes [7]. During an individual's undergraduate education, students acquire lifestyle behaviors that, in the majority of cases, are maintained in adulthood [8]. Hence, this population represents a key target for health promotion and prevention activities and is the focus of the present study.

During the first semester of 2020, especially during population lockdowns, multiple studies have shown the remarkable impact of COVID-19 pandemic on most lifestyle behaviors of undergraduate students. Thus, significant rates of sleep disturbances have been observed $[9,10]$, as well as decreased physical activity levels and increased sedentary behaviors [9,11-13]. A worsening of nutritional and diet quality was also described [14], although a greater adherence to the Mediterranean diet was observed [15] during confinement. Changes have also been demonstrated with respect to substance use [16], such as increased alcohol consumption. Increased use of digital technologies and screen time have also been shown [9], especially among students with psychiatric morbidity and low levels of exercise [17]. Moreover, significant rates of depression, anxiety, and psychological stress have been described among undergraduate students during the pandemic $[18,19]$. Interestingly, worsened mental health has been related with lifestyle changes in this population [20].

In summary, several studies have described lifestyle changes in undergraduate students during the current pandemic. However, most research so far has focused on some specific areas of healthy lifestyles separately or have used ad hoc, non-validated instruments. In this sense, the Short Multidimensional Inventory Lifestyle Evaluation (SMILE-C) questionnaire was developed and validated during the current pandemic to simultaneously evaluate different dimensions of lifestyle [21]. Moreover, while previous research has been conducted during the first months of the pandemic, longer-term effects have received much less attention. Finally, to our knowledge, no previous studies have included a control group of non-university student participants.

Based on the above, the present study aims to analyze lifestyle changes in undergraduate students, several months after the onset of the pandemic, from a multidimensional perspective (e.g., diet and nutrition, substance use, physical activity, stress management, restorative sleep, social support, and environmental exposures). The main study goal was to describe and compare lifestyles during the survey period between students and a control group of participants matched by age and sex. The secondary objectives were to measure the frequency of mental health problems (depression, anxiety, and alcohol abuse) and to identify independent predictors of healthy lifestyles for each group. 


\section{Materials and Methods}

\subsection{Study Design}

This analysis profits from data collected in an online survey conducted from 16 November to 16 December 2020. The online questionnaire was programmed in SurveyGizmo ${ }^{\circledR}$ (http: / / www.surveygizmo.com.br/ (accessed on 1 November 2020)) and included questions about lifestyle behaviors, and their changes related with the pandemic, demographics, COVID-19 experience, self-rated health, and previous diagnosed conditions, as described elsewhere [21,22]. The survey followed a similar methodology used by our research team during the early pandemic [21,22].

During the survey period, eight months after the declaration of the state of alarm due to the pandemic, restrictions such as home confinement were not issued in Spain. However, the rules for social distancing were reinforced, curfew was established, and the mandatory use of a mask and restriction of mobility between territories were both imposed.

\subsection{Study Population}

The online survey included 3635 adults over 18 years from both sexes living in Spain with internet access who agreed to participate in the study after reading the informed consent form. To avoid the same individuals from answering multiple times, it was asked whether the survey had been answered previously.

For the present study, we selected 221 participants reporting to be undergraduate student, and 221 participants matched by sex and age (range of \pm 3 years) who reported not studying or did so in non-university education. The NumPy and Pandas libraries of Python were used, through the Spyder open-source platform for scientific programming, to manipulate and manage the data. The pairing algorithm excludes the already selected individuals to form the subsequent pairs. To avoid repeated responses, it was specifically asked whether the survey had already been answered previously. Thus, the final 221 pairs contain unique individuals. Postgraduate students (e.g., those with a masters or doctorate degree) were excluded from the analyses.

\subsection{Sampling and Recruitment}

The convenience online sample was obtained via social networks (Twitter, Facebook, and WhatsApp), and mailing lists. A snowball technique (i.e., individuals who answered the questionnaire were asked to send the survey link to their contacts) was used. Since the fundamental parameters were unknown at the moment defining sample size, it was not defined a priori. Instead, a 30 day-period of data collection was specified.

\subsection{Outcome Variable}

The main outcome variable was global lifestyle, evaluated using the total score on the SMILE-C [21] scale. This tool was developed from the original SMILE, which is a selfassessed 43-item questionnaire comprising seven lifestyle habits or domains: diet/nutrition, substance abuse, physical activity, stress management, restorative sleep, social support, and environmental exposure. It was developed to carry out a multidimensional and comprehensive assessment of a (healthy) lifestyle during the previous 30 days.

The SMILE-C scale analyses in a global way the lifestyle during the last 30 days, with a questionnaire of 27 items belonging to the seven domains mentioned. The response options have been measured using a 4-point Likert-type scale, the final score being obtained by adding the scores of all the questions (taking into account that some questions have inverse scores). The higher the score, the healthier the lifestyle (scores range from 27 to 108). In a previous publication, it was found that the SMILE-C scale presents a global Cronbach's alpha of 0.75 and a Kaiser-Meyer-Olkin coefficient $=0.77$ [21].

\subsection{Variables and Measurements}

Demographic information included sex, gender, age, local measures to fight against COVID-19 (with options: no measures, perimetral confinement, home confinement), ed- 
ucational level, number of cohabitants at home, and self-isolation by contagion or risk contact. The COVID-19 questions were related to diagnosis (yes/no), need of hospitalization (yes/no) or ventilation (yes/no) and loss of significant ones (yes/no).

Self-rated health (SRH) was measured using the question "How would you rate your health in general?" with possible answer choices of "Very bad", "Bad", "Regular", "Good" and "Very good". The response options were aggregated into Very good/Good and Regular/Bad/Very bad.

Change in lifestyle behaviors during the COVID-19 pandemic as compared to before the pandemic was assessed by questions such as: "Did you change your (nutritional habits and diet) during the COVID-19 pandemic?", with a 4-point Likert-type response (Totally, Moderately, Mildly, or Not at all), being aggregated into Totally/Moderately and Mildly/Not at all. To assess whether these changes were towards a more or less healthy lifestyle, we used the question "You consider that your (nutritional habits and diet) nowadays are ..." ", with three possible answers, "As healthy as before", "Healthier than before" or "Less healthy than before".

Previously diagnosed conditions were self-reported using the question "In the last 12 months, have you been diagnosed by a medical doctor or health professional, or received treatment for any of the following conditions?". Possible health problems investigated included diabetes, heart disease, hypertension, anemia, asthma, depression, anxiety, schizophrenia, bipolar disorder, anorexia/bulimia nervosa, HIV / AIDS, cancer, tuberculosis, cirrhosis, renal disease, and others.

Current depression was screened using the Patient Health Questionnaire-2 (PHQ2) [23] using a cut-off $\geq 3$, and current anxiety was screened using the Generalized Anxiety Disorder 7-item (GAD-7) [24] using a cut-off $\geq 10$. Two dichotomous variables were created "Positive Screening for Depression" and "Positive Screening for Anxiety". Then a composite variable was created using these variables with the following categories: no positive screening, positive screening for depression only, positive screening for anxiety only, and positive screening for both. Screening for alcohol abuse was performed using the Alcohol Use Disorders Identification Test Consumption Questions (AUDIT-C) [25] and cut-off was $\geq 3$.

\subsection{Statistical Analysis}

Following the study methodology of the first survey [21], the mean and standard deviation of the SMILE-C scores were calculated for all the control group and of undergraduate students' variables. Normality of distribution was tested for all the variables using the Kolmogorov-Smirnov test. Therefore, statistically significant differences were evaluated using non-parametric tests. For the bivariate associations between dichotomous variables and the SMILE-C scores, Mann-Whitney U test was used. The McNemar test was used for lifestyle changes and mental health between the paired groups. The independent variables were described by results and compared proportions using $\chi 2$. The bivariate associations between age and the number of people living in the household and the SMILE-C score were evaluated using the Spearman correlation tests.

In order to analyze between-group differences in SMILE-C scores, a multivariate linear regression model was performed to control the potential influence of covariates where the group (undergraduate students/controls) and all variables associated with the SMILE-C with $p<0.20$ were entered as independent variables. Multivariate linear regression models were also performed to evaluate the effect of independent factors on the total SMILE-C score of each group. Initial models included variables associated with the SMILE-C with $p<0.20$ in the bivariate analyses. In order to find out the B of each category of the categorical variables, dummy variables (binary) were created for each category of them. A final model was reached for each group, using a manual stepwise removal of each non-significant variable, and evaluating the changes in the remaining $\mathrm{B}$. 


\subsection{Ethical Aspects}

The study was approved by the Ethics Committee at the Hospital Universitari i Politècnic La Fe, in Valencia, Spain (2020-149-1). The surveys were anonymous (no identification -name-, city or IP address was collected) and participants read the consent form and confirmed their interest in participating in the first screen of the online questionnaires.

\section{Results}

A sample of 442 matched participants by age and sex was selected for our study (221 undergraduate students and 221 individuals who were not studying or did so in nonuniversity education). Table 1 describe the sociodemographic and clinical characteristics of the sample, COVID-19 related experiences, and the respective SMILE-C means and their bivariate association.

Table 1. Sociodemographic, COVID-19 related experiences, health-related variables and mean SMILE-C score.

\begin{tabular}{|c|c|c|c|c|c|c|}
\hline \multirow[b]{2}{*}{ Variables } & \multicolumn{3}{|c|}{ Controls } & \multicolumn{3}{|c|}{ Undergraduate Students } \\
\hline & n (\%) & $\begin{array}{c}\text { SMILE-C } \\
\text { Mean (SD)/r }\end{array}$ & $p$-Value & n (\%) & $\begin{array}{c}\text { SMILE-C } \\
\text { Mean (SD)/r }\end{array}$ & $p$-Value \\
\hline \multicolumn{7}{|c|}{ Sex } \\
\hline Male & $59(26.70)$ & $76.85(7.25)$ & \multirow{2}{*}{0.449} & $59(26.70)$ & $80.95(9.33)$ & \multirow{2}{*}{0.086} \\
\hline Female & $162(73.30)$ & $77.34(8.68)$ & & $162(73.30)$ & $79.4(7.65)$ & \\
\hline Age* & $23(21-25)$ & $\mathrm{r}=0.076$ & 0.259 & $22(21-23)$ & $\mathrm{r}=-0.002$ & 0.979 \\
\hline Number of cohabitants * & $3.0(2.5-4.0)$ & $\mathrm{r}=0.129$ & 0.056 & $4.0(3.0-4.0)$ & $\mathrm{r}=0.108$ & 0.109 \\
\hline \multicolumn{7}{|c|}{ COVID-19 diagnosis } \\
\hline No & $203(91.90)$ & $76.99(8.32)$ & \multirow{2}{*}{0.101} & $209(94.57)$ & $79.58(8.13)$ & \multirow{2}{*}{0.132} \\
\hline Yes & $18(8.10)$ & $79.67(8.06)$ & & $12(5.43)$ & $83.83(7.47)$ & \\
\hline \multicolumn{7}{|c|}{ Lost somebody in the pandemic } \\
\hline No & $204(92.30)$ & $77.25(8.14)$ & \multirow{2}{*}{0.591} & $202(91.40)$ & $79.8(8.02)$ & \multirow{2}{*}{0.817} \\
\hline Yes & $17(7.70)$ & $76.64(10.40)$ & & $19(8.60)$ & $80.0(9.57)$ & \\
\hline \multicolumn{7}{|c|}{ Economic difficulties during the pandemic } \\
\hline No & $151(68.30)$ & 79.09 (6.93) & \multirow{3}{*}{$<0.001$} & $179(81.00)$ & $80.88(7.36)$ & \multirow{3}{*}{0.005} \\
\hline Yes & $58(26.20)$ & $73.74(8.89)$ & & $28(12.67)$ & $75.18(8.33)$ & \\
\hline Prefer not to answer & $12(5.40)$ & $70.33(12.44)$ & & $14(6.33)$ & $75.5(12.43)$ & \\
\hline \multicolumn{7}{|c|}{ Self-rated health } \\
\hline Very good or good & $176(79.64)$ & $79.19(6.78)$ & \multirow{2}{*}{$<0.001$} & $192(86.88)$ & $81.12(7.16)$ & \multirow{2}{*}{$<0.001$} \\
\hline Regular, bad or very bad & $45(20.36)$ & $69.47(9.24)$ & & $29(13.12)$ & $71.17(9.03)$ & \\
\hline \multicolumn{7}{|c|}{ Diagnosed or treated for mental illness during the last year } \\
\hline No & $176(79.64)$ & $78.36(7.74)$ & \multirow{2}{*}{$<0.001$} & $175(79.18)$ & $81.01(7.53)$ & \multirow{2}{*}{$<0.001$} \\
\hline Yes & $45(20.36)$ & $72.69(8.99)$ & & $46(20.81)$ & $75.28(8.86)$ & \\
\hline \multicolumn{7}{|c|}{ Screening for depression and anxiety } \\
\hline Negative for both depression and anxiety & $123(55.66)$ & $80.17(6.90)$ & \multirow{4}{*}{$<0.001$} & $142(64.25)$ & $82.94(6.90)$ & \multirow{4}{*}{$<0.001$} \\
\hline Positive for depression only & $16(7.24)$ & $75.12(6.56)$ & & $16(7.24)$ & $74.18(6.36)$ & \\
\hline Positive for anxiety only & $30(13.57)$ & $75.43(5.97)$ & & $15(6.79)$ & $78.6(6.43)$ & \\
\hline Positive for both depression and anxiety & $52(23.53)$ & $71.86(9.89)$ & & $48(21.72)$ & $72.83(7.20)$ & \\
\hline \multicolumn{7}{|c|}{ Screening for alcohol abuse } \\
\hline Negative & $184(83.26)$ & $77.47(8.11)$ & \multirow{2}{*}{0.541} & $188(85.07)$ & $79.79(8.25)$ & \multirow{2}{*}{0.978} \\
\hline Positive & $37(16.74)$ & $75.92(9.27)$ & & $33(14.93)$ & $79.94(7.59)$ & \\
\hline \multicolumn{7}{|c|}{ Diagnosed or treated for schizophrenia/bipolar disorder/anorexia/bulimia in the previous year } \\
\hline No & $214(96.83)$ & $77.51(7.97)$ & \multirow{2}{*}{0.036} & $216(97.73)$ & $79.82(8.16)$ & 0977 \\
\hline Yes & $7(3.17)$ & $68.0(13.19)$ & & $5(2.62)$ & $79.40(8.08)$ & 0.978 \\
\hline
\end{tabular}


Table 1. Cont.

\begin{tabular}{|c|c|c|c|c|c|c|}
\hline \multirow[b]{2}{*}{ Variables } & \multicolumn{3}{|c|}{ Controls } & \multicolumn{3}{|c|}{ Undergraduate Students } \\
\hline & n (\%) & $\begin{array}{c}\text { SMILE-C } \\
\text { Mean (SD)/r }\end{array}$ & $p$-Value & n (\%) & $\begin{array}{c}\text { SMILE-C } \\
\text { Mean (SD)/r }\end{array}$ & $p$-Value \\
\hline \multicolumn{7}{|c|}{ Diagnosed or treated for diabetes in the previous year } \\
\hline No & $212(95.93)$ & $77.39(8.31)$ & \multirow{2}{*}{0.088} & $217(98.20)$ & $79.83(8.10)$ & \multirow{2}{*}{0.893} \\
\hline Yes & $9(4.07)$ & $72.89(7.47)$ & & $4(1.80)$ & $78.75(11.44)$ & \\
\hline \multicolumn{7}{|c|}{ Diagnosed or treated for asthma/bronchitis in the previous year } \\
\hline No & $205(92.76)$ & $77.26(8.42)$ & \multirow{2}{*}{0.483} & $207(93.70)$ & $79.77(8.23)$ & \multirow{2}{*}{0.836} \\
\hline Yes & $16(7.24)$ & $76.56(7.01)$ & & $14(6.30)$ & $80.50(6.97)$ & \\
\hline \multicolumn{7}{|c|}{ Diagnosed or treated for heart disease or hypertension in the previous year } \\
\hline No & $211(95.47)$ & $77.21(8.41)$ & \multirow{2}{*}{0.929} & $218(98.60)$ & $79.79(8.15)$ & \multirow{2}{*}{0.585} \\
\hline Yes & $10(4.53)$ & $77.20(6.30)$ & & $3(1.40)$ & $81.67(9.29)$ & \\
\hline \multicolumn{7}{|c|}{ Diagnosed or treated for chronic disease in the previous year } \\
\hline No & $179(81.00)$ & $77.61(8.62)$ & \multirow{2}{*}{0.044} & $185(83.71)$ & $79.87(8.17)$ & \multirow{2}{*}{0.977} \\
\hline Yes & $42(19.00)$ & $75.5(6.66)$ & & $36(16.29)$ & $79.53(8.10)$ & \\
\hline \multicolumn{7}{|c|}{ Diagnosed or treated for others (HIV/AIDS, tuberculosis, cancer, cirrhosis, kidney disease, other) } \\
\hline No & $192(86.88)$ & $77.69(7.91)$ & \multirow{2}{*}{0.061} & $192(86.88)$ & $79.98(7.84)$ & \multirow{2}{*}{0.669} \\
\hline Yes & $29(13.12)$ & $74.00(10.15)$ & & $29(13.12)$ & $78.68(9.98)$ & \\
\hline
\end{tabular}

SMILE-C: Short Multidimensional Inventory Lifestyle Evaluation, SD: Standard Deviation, ${ }^{*}$ Median (Interquartile range)

Regarding sociodemographic variables, almost three quarters of the sample (73.3\%) was composed of women. Participants were demographically distributed as follows: $38.9 \%$ from the Valencian Community, 34.6\% from Andalusia, and 26.5\% from other regions. The mean age for the undergraduate students was $21.86 \pm 2.12$ years and $22.86 \pm 2.48$ years for controls. In both groups, none of the sociodemographic variables were significantly associated with the SMILE-C score (Table 1), although in controls a non-significant trend was observed for the number of people living in the household. In both groups, having experienced financial difficulties during the pandemic was the only variable significantly associated with lower SMILE-C scores (Table 1). No other COVID-19 related variables were associated with the SMILE-C score.

In the control group, higher SMILE-C scores were associated with several healthrelated variables: very good or good $\mathrm{SRH}$, not being diagnosed or treated in the previous year of mental illness, psychiatric disorders (schizophrenia/bipolar disorder/anorexia/ bulimia), or other diseases (HIV / AIDS, tuberculosis, cancer, cirrhosis, other), and having a negative screening for depression and anxiety. In the group of students, the following variables were associated with higher SMILE-C scores: very good or good SRH, no history of mental illness, and a negative screening for depression and anxiety. In contrast, positive screening for alcohol abuse was not associated with SMILE-C total scores in either of the two groups.

\subsection{Comparison of Lifestyle Behaviours and Mental Health}

Undergraduate students presented a higher mean SMILE-C score than controls $(79.81 \pm 8.14$ vs. $77.21 \pm 8.31, p<0.001)$. However, after controlling the effect of several covariates on the SMILE-C score, these differences disappeared $(p=0.162)$. A regression model including number of cohabitants $(p=0.001)$, self-rated health $(p<0.001)$, screening for anxiety $(p<0.001)$, economic difficulties during the pandemic $(p<0.001)$, and changes in stress management $(p<0.001)$ and in restorative sleep $(p=0.006)$ explained $35.7 \%$ of variance in SMILE-C mean scores $\left(\mathrm{F}=34.36, \mathrm{R}^{2}=0.357, p<0.001\right)$.

Groups did not differ in the screenings of depression and alcohol abuse, although significant differences were found for the screening of anxiety. Regarding the proportion of relevant changes (totally/moderate) in the seven lifestyle habits, groups only differed in diet/nutrition and restorative sleep. In both cases, the changes were more relevant in controls (Table 2). 
Table 2. Between-group comparison of mental health screenings and lifestyle changes.

\begin{tabular}{|c|c|c|c|}
\hline Variables & $\begin{array}{l}\text { Controls } \\
\text { n (\%) }\end{array}$ & $\begin{array}{l}\text { Undergraduate Students } \\
\text { n (\%) }\end{array}$ & $p$-Value \\
\hline \multicolumn{4}{|c|}{ Screening of alcohol abuse } \\
\hline Negative & $184(83.3)$ & $188(85.1)$ & \multirow{2}{*}{0.093} \\
\hline Positive & $37(16.7)$ & $33(14.9)$ & \\
\hline \multicolumn{4}{|c|}{ Screening of depression } \\
\hline Negative & $153(69.2)$ & $157(71.0)$ & \multirow{2}{*}{0.077} \\
\hline Positive & $68(30.8)$ & $64(29.0)$ & \\
\hline \multicolumn{4}{|c|}{ Screening of anxiety } \\
\hline Negative & $139(62.9)$ & $158(71.5)$ & \multirow{2}{*}{0.042} \\
\hline Positive & $82(37.1)$ & $63(28.5)$ & \\
\hline \multicolumn{4}{|c|}{ Lifestyle changes: } \\
\hline \multicolumn{4}{|c|}{ Diet and nutrition } \\
\hline Mild/no changes & $156(70.6)$ & $178(80.5)$ & \multirow{2}{*}{0.018} \\
\hline Totally/moderate changes & $65(29.4)$ & $43(19.5)$ & \\
\hline \multicolumn{4}{|c|}{ Substance abuse } \\
\hline Mild/no changes & $178(80.5)$ & $189(85.5)$ & \multirow{2}{*}{0.228} \\
\hline Totally/moderate changes & $43(19.5)$ & $32(14.5)$ & \\
\hline \multicolumn{4}{|c|}{ Physical activity } \\
\hline Mild/no changes & $112(50.7)$ & $120(54.3)$ & \multirow{2}{*}{0.497} \\
\hline Totally/moderate changes & $109(49.3)$ & $101(45.7)$ & \\
\hline \multicolumn{4}{|c|}{ Stress management } \\
\hline Mild/no changes & $139(62.9)$ & $154(69.7)$ & \multirow{2}{*}{0.137} \\
\hline Totally/moderate changes & $82(37.1)$ & $67(30.3)$ & \\
\hline \multicolumn{4}{|c|}{ Restorative sleep } \\
\hline Mild/no changes & $153(69.2)$ & $176(79.6)$ & \multirow{2}{*}{0.022} \\
\hline Totally/moderate changes & $68(30.8)$ & $45(20.4)$ & \\
\hline \multicolumn{4}{|c|}{ Social support } \\
\hline Mild/no changes & $144(65.2)$ & $161(72.9)$ & \multirow{2}{*}{0.111} \\
\hline Totally/moderate changes & $77(34.8)$ & $60(27.1)$ & \\
\hline \multicolumn{4}{|c|}{ Environmental exposures } \\
\hline Mild/no changes & $137(62.0)$ & $156(70.6)$ & \multirow{2}{*}{0.078} \\
\hline Totally/moderate changes & $84(38.0)$ & $65(29.4)$ & \\
\hline
\end{tabular}

\subsection{Changes on Lifestyle Behaviours during the COVID-19 Pandemic}

The self-reported changes in lifestyle behaviors during the COVID-19 pandemic are depicted for both groups (Figures 1 and 2). Table 3 shows the distribution of these changes between both groups. Significant differences were found in environmental exposures only. Compared with the controls, a higher proportion of undergraduate students, maintained their habits of environmental exposures just as healthy as before the pandemic. 


\section{Undergraduate students}

Environmental exposures

Social support

Sleep pattern

Stress management

Physical activity

Substance abuse

Diet and nutrition

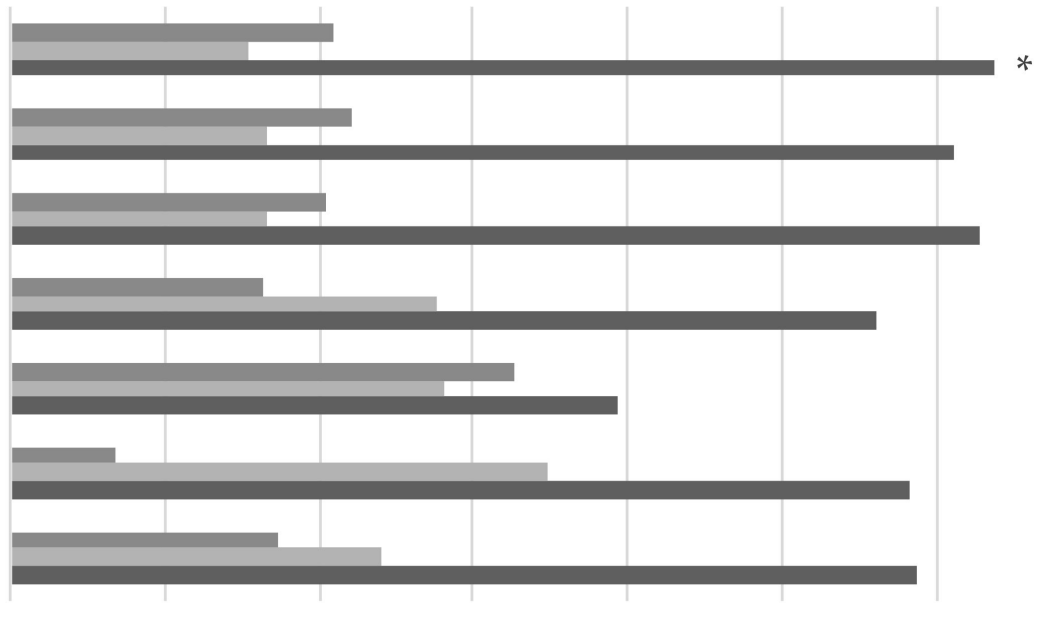

$\begin{array}{llllllll}0 & 10 & 20 & 30 & 40 & 50 & 60 & 70\end{array}$

Less healthy than before $\quad$ Healthier than before $\quad$ As healthy as before

Figure 1. Self-reported changes on lifestyle behaviors during the COVID-19 pandemic in undergraduate students. ${ }^{*}$ Significant differences $(p=0.004)$.

\section{Controls}

\section{Environmental exposures \\ Social support \\ Sleep pattern}

Stress management

Physical activity

Substance abuse

Diet and nutrition
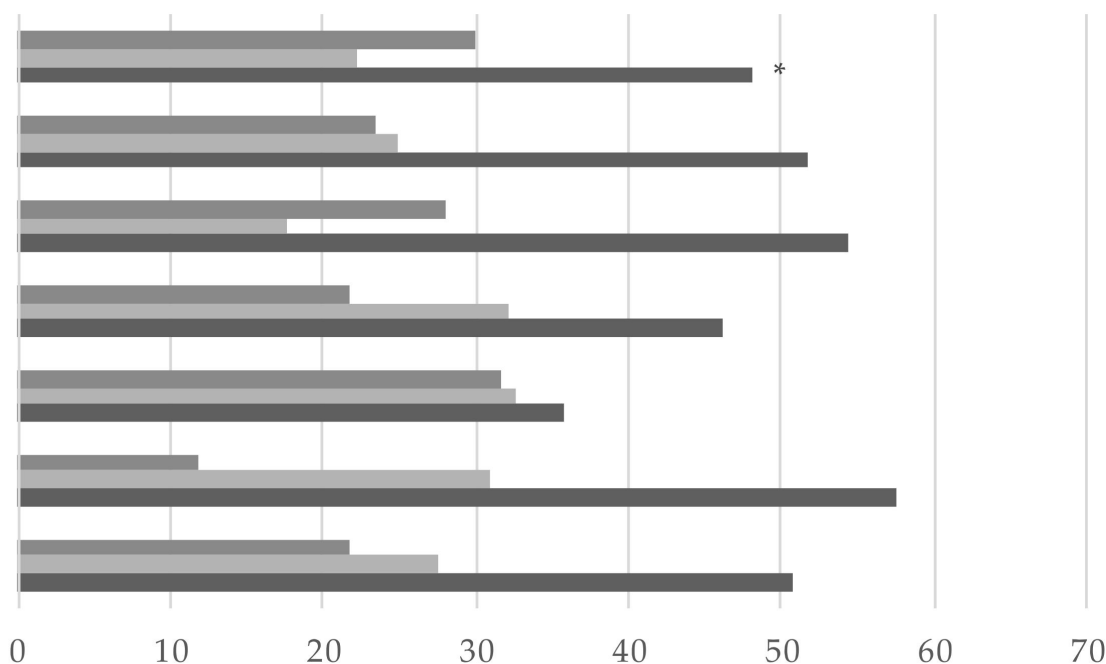

Less healthy than before Healthier than before $\quad$ As healthy as before

Figure 2. Self-reported changes on lifestyle behaviors during the COVID-19 pandemic in controls. ${ }^{*}$ Significant differences $(p=0.004)$.

\subsection{Variables Independently Associated with Lifestyle Behaviours}

The final multivariate models for both groups are shown on Tables 4 and 5. For the control group (Table 4), the variables that remained independently associated with higher SMILE-C scores were a higher number of people living in the household and the total/moderate changes in stress management. A worse SRH, a positive screening for depression/anxiety, and total/moderate changes in substance abuse were associated with lower SMILE-C scores. 
Table 3. Self-reported changes on lifestyle behaviors compared with before the pandemic.

\begin{tabular}{|c|c|c|c|}
\hline Variables & $\begin{array}{l}\text { Controls } \\
\text { n (\%) }\end{array}$ & $\begin{array}{l}\text { Undergraduate Students } \\
\text { n (\%) }\end{array}$ & $p$-Value \\
\hline \multicolumn{4}{|c|}{ Diet and nutrition } \\
\hline As healthy as before & $112(50.7)$ & $130(58.8)$ & \multirow{3}{*}{0.216} \\
\hline Healthier than before & $61(27.6)$ & $53(24.0)$ & \\
\hline Less healthy than before & $48(21.7)$ & $38(17.2)$ & \\
\hline \multicolumn{4}{|c|}{ Substance abuse } \\
\hline As healthy as before & $127(57.5)$ & $129(58.4)$ & \multirow{3}{*}{0.172} \\
\hline Healthier than before & $68(30.8)$ & $77(34.8)$ & \\
\hline Less healthy than before & $26(11.8)$ & $15(6.8)$ & \\
\hline \multicolumn{4}{|c|}{ Physical activity } \\
\hline As healthy as before & $79(35.7)$ & $87(39.4)$ & \multirow{3}{*}{0.56} \\
\hline Healthier than before & $72(32.6)$ & $62(28.1)$ & \\
\hline Less healthy than before & $70(31.7)$ & $72(32.6)$ & \\
\hline \multicolumn{4}{|c|}{ Stress management } \\
\hline As healthy as before & $102(46.2)$ & $124(56.1)$ & \multirow{3}{*}{0.1} \\
\hline Healthier than before & $71(32.1)$ & $61(27.6)$ & \\
\hline Less healthy than before & $48(21.7)$ & $36(16.3)$ & \\
\hline \multicolumn{4}{|c|}{ Restorative sleep } \\
\hline As healthy as before & $120(54.3)$ & $139(62.9)$ & \multirow{3}{*}{0.126} \\
\hline Healthier than before & 39 (17.6) & 37 (16.7) & \\
\hline Less healthy than before & $62(28.1)$ & $45(20.4)$ & \\
\hline \multicolumn{4}{|c|}{ Social support } \\
\hline As healthy as before & $114(51.6)$ & $135(61.1)$ & \multirow{3}{*}{0.068} \\
\hline Healthier than before & $55(24.9)$ & 37 (16.7) & \\
\hline Less healthy than before & $52(23.5)$ & $49(22.2)$ & \\
\hline \multicolumn{4}{|c|}{ Environmental exposures } \\
\hline As healthy as before & $106(48.0)$ & $141(63.8)$ & \multirow{3}{*}{0.004} \\
\hline Healthier than before & $49(22.2)$ & $34(15.4)$ & \\
\hline Less healthy than before & $66(29.9)$ & $46(20.8)$ & \\
\hline
\end{tabular}

Table 4. Factors associated with better SMILE-C scores in the control group.

\begin{tabular}{ccc}
\hline Variables & \multicolumn{2}{c}{ Controls } \\
\cline { 2 - 3 } & B CI (95\%) & $p$-Value \\
\hline Number of cohabitants & $1.057(0.195-1.919)$ & 0.017 \\
\hline Very good or good & Self-rated health & \\
\hline Regular, poor or very poor & Reference & $<0.001$ \\
\hline
\end{tabular}


Table 4. Cont.

\begin{tabular}{ccc}
\hline \multirow{2}{*}{ Variables } & B CI (95\%) & $p$-Value \\
\cline { 2 - 3 } & Screening for depression and anxiety & \\
\hline Negative for both anxiety and depression & Reference & 0.03 \\
\hline Positive for depression only & $-3.958(-7.531-0.385)$ & 0.009 \\
\hline Positive for anxiety only & $-3.679(-6.425-0.934)$ & $<0.001$ \\
\hline Positive for both depression and anxiety & $-5.626(-8.002-3.25)$ & 0.042 \\
\hline Mild/no changes & Substance abuse & \\
\hline Totally/moderate changes & Reference & \\
\hline Mild/no changes & $-2.422(-4.759-0.085)$ & 0.002 \\
\hline Totally/moderate changes & Stress management & \\
\hline
\end{tabular}

Table 5. Factors associated with better SMILE-C score among the undergraduate students group.

\begin{tabular}{|c|c|c|}
\hline \multirow{2}{*}{ Variables } & \multicolumn{2}{|c|}{ Undergraduate Students } \\
\hline & B CI (95\%) & $p$-Value \\
\hline Number of cohabitants & $1.101(0.249-1.953)$ & 0.012 \\
\hline \multicolumn{3}{|c|}{ Self-rated health } \\
\hline Very good or Good & Reference & \\
\hline Regular, bad or very bad & $-5.729(-8.494-2.964)$ & $<0.001$ \\
\hline \multicolumn{3}{|c|}{ Screening for depression and anxiety } \\
\hline Negative for both anxiety and depression & Reference & \\
\hline Positive for depression only & $-7.575(-10.921-4.230)$ & $<0.001$ \\
\hline Positive for anxiety only & $-2.890(-6.382-0.603)$ & 0.104 \\
\hline Positive for both depression and anxiety & $-7.341(-9.677-5.006)$ & $<0.001$ \\
\hline \multicolumn{3}{|c|}{ Diagnosed or treated for a mental illness in the previous year } \\
\hline No & Reference & \\
\hline Yes & $-2.379(-4.632-0.127)$ & 0.039 \\
\hline \multicolumn{3}{|c|}{ Economic difficulties during the pandemic } \\
\hline No & Reference & \\
\hline Yes & $-2.665(-5.325-0.004)$ & 0.050 \\
\hline Prefer not to respond & $-3.932(-7.485-0.379)$ & 0.030 \\
\hline
\end{tabular}

For students (Table 5), the number of people living in the household was the only variable that remained independently associated with higher SMILE-C scores. In contrast, a worse Self-Rated Health, a positive screening only for depression or depression and anxiety, having a history of mental illness, and having experienced financial issues during the pandemic were associated with lower SMILE-C scores.

\section{Discussion}

In this online survey conducted several months after the lockdown in Spain, overall lifestyle measured by the total score on the SMILE-C scale was healthier among undergraduate students compared to that of sex and age-matched participants from the general population in Spain. However, when controlling for covariates, these differences were no 
longer significant. Positive screenings for anxiety were significantly higher in the control group and non-significant trends in the same direction were also observed for screenings for depression and alcohol abuse. Moreover, this study further confirms the important association between mental health and healthy lifestyles in a general population sample and expands this finding to undergraduate students.

Both groups showed similar lifestyles during the survey period. The interpretation of this innovative finding is hindered by the absence of previous studies comparing undergraduate students with matched controls. As a more educated group, students are expected to have a higher health literacy [26]. Indeed, a higher literacy on a healthy diet has been reported to be associated with healthier eating behaviors among undergraduate students during the current pandemic [27]. However, according to the present results, that would not drive a major advantage over controls in adherence to a healthier lifestyle. Of note, differences in lifestyles between groups became non-significant once several potential confounders were taken into account. In particular, the number of cohabitants, self-rated health, screening for anxiety, having experienced financial difficulties during the pandemic, and changes in stress management and in restorative sleep were all significantly associated with SMILE-C scores.

Regarding mental health problems, about $30 \%$ of the undergraduate students had a positive screening for either depression or anxiety, while alcohol abuse was suspected in $15 \%$. Overall, these rates were lower than those of the control participants in this study, as mentioned above. The COVID-19 pandemic has notoriously affected the mental health of the general population [28,29]. According to a recent meta-analysis [30], the prevalence of anxiety does not seem to have increased during the COVID-19 pandemic in medical students, although increased stress has been found in other undergraduate students [18]. Prior to the pandemic, substantial evidence supports that undergraduate students have higher rates of anxiety than the general population [31]. Taken together, it could be speculated that anxiety likely increased in both groups of this survey, but more so in controls, until they significantly exceeded those of undergraduate students.

It is likely that getting earlier and a higher amount of information about the pandemic, as well as higher resilience developed throughout the grades, can protect students against stress-related symptoms. Conversely, the greater likelihood of experiencing financial difficulties seems to be a risk factor for controls. These hypotheses could also apply to depression and await confirmation with further comparative, ideally longitudinal, studies.

When each lifestyle habit was compared between groups, statistically significant differences arose only in diet/nutrition and restorative sleep. In both cases, students had a lower percentage of totally/moderate changes than the controls. Despite having taken online lessons on many occasions, students may have also continued to maintain a regular schedule of chores over the pandemic, which in turn may account for these findings.

In undergraduate students, physical activity was the lifestyle behavior most sensitive to the recent effects of the pandemic, since almost half of the sample reported totally/moderate relevant changes during the previous month. These results converge with those of previous studies that analyzed changes in physical activity [9,11,12,32]. Moreover, physical activity is among the most common strategies to help with mental wellbeing [33], which further emphasizes the link between lifestyles and common mental symptoms [34]. Lagging behind physical activity, one third of students reported having experienced relevant changes over the previous month in stress management, environmental exposures, and social support. Previous surveys suggest that stress was higher among respondents with sleep problems [35], substance use [20], alcohol-related problems, eating problems, and problematic internet use [36]. Moreover, those spending at least two hours outside, or less than eight hours engaged on electronic screens, were likely to experience lower levels of psychological impact [37]. Our results are also consistent with those of other studies [9,15], which found that screen time has increased substantially during the pandemic. Moreover, a lower perception of social support was associated with increased depressive symptoms in undergraduate students during the third wave in Hong Kong [38]. 
As another remarkable finding of this survey, lifestyles of all of the students remained mostly unchanged compared to those before the pandemic. Regarding substance use, more than a third of participants claimed to have healthier habits than before the pandemic. This is an expected finding given the substantial pandemic-related decrease in social activities that could worsen overall lifestyle. These results are also consistent with reduced alcohol use previously reported in a university sample [39].

Changes compared to before the pandemic observed in students significantly differed from those of controls for environmental exposures only. Before the COVID-19, students were already used to spending a large amount of time with screens as part of their learning chores. Although a longer screen time has been observed during the pandemic, this increase has been lower than that in non-university participants.

Despite the fact that both groups showed similar lifestyles, several variables were independently associated with healthier or unhealthier lifestyles. For both groups, selfperceiving a good state of health was strongly associated with a healthier lifestyle. We believe that this result gives value to this questionnaire since the participants who report having a worse state of health are in turn those who obtain a lower total score on the SMILEC (i.e., an unhealthier overall lifestyle). Secondly, a greater number of cohabitants was also associated with healthier lifestyles in both groups. Related with this, the restriction of social interaction outside the home could improve the relationships with cohabitants, which in turn may favour strengthening social support. Moreover, living with more people could have favored the organization of daily routines, and even the collaborative improvement of lifestyle such as sharing meals and exercise routines. Previous studies have shown gender differences in attitudes and behaviors [40,41], as well as several mental health outcomes [42] during the COVID-19 pandemic. However, in this study no significant gender differences were observed in either group regarding overall lifestyles.

In undergraduate students, the risk for a less healthy lifestyle was higher in those with a history of mental illness in the previous year or a probable depression with or without anxiety, compared with those with a negative screening for both common mental disorders. Several studies have found that poor mental health is associated with lifestyle in undergraduate students. For instance, a relationship between anxiety symptoms and sleep problems has been described [43], whereas engaging in physical activity [44] and a higher perceived social support [20,38] reduced the likelihood of anxiety. Moreover, depressive symptoms seem to be more prevalent among students with sleep problems [43], higher screen time [38,45], decreased physical activity [46,47], poor social support [20], and smoking or alcohol consumption [33]. The present results are also consistent with previous evidence showing that psychiatric disorders, in general, are associated with unhealthy lifestyle behaviors [48]. In addition, a close relationship was observed between unhealthier lifestyles and having experienced economic difficulties during the pandemic, as well as with the preference for not answering this question. This is an expected result since a lower purchasing power is usually associated with poorer lifestyles.

The interpretation of the present findings must be understood in the context of several limitations. Firstly, the external validity of the results is constrained by the representativeness of the sample. At the moment, web surveys are still considered non-probability samples, as the probability of inclusion of each individual is unknow and individuals without access to the web have a null chance to be included. Thus, this sample is not representative neither from the Spanish general population nor the Spanish undergraduate students. As in other web surveys performed during the pandemic, women were overrepresented in our sample $(73 \%)[9,11,12,49,50]$ as compared to the percentage of women in the university (55\%) [51] and in the Spanish population (approximately 50\%) [52]. In addition, only $37.5 \%$ [53] of the Spanish population has an undergraduate degree and our results must be interpreted with caution.

Secondly, the analysis of lifestyle changes was based on self-reported perception, which is subject to social desirability and memory bias. New technologies, such as personal health trackers, can be helpful in overcoming these limitations in the future. Thirdly, the 
SMILE-C was designed to use a 4-point Likert-type scale (always, often, seldom, never). This might be seen as a limitation since it may force respondents to not give neutral answers. Whether or not offering a central or middle point in a Likert-type scale has been disputed for decades. The original meaning of the midpoint is neutral or indifferent, for instance 'neither agree nor disagree'. Likert scales with an uneven number of options, usually five or seven, are the standard to measure degree of (dis)agreement. Nevertheless, the SMILE-C measures the frequency of a given lifestyle behavior, instead. Moreover, this is a complex issue. Although Likert scales with four or seven points have been found to have the strongest support in terms of reliability and validity [54], less research has examined changes to the characteristics of the data when a midpoint is utilized [55]. In addition, Garland [56] found that social desirability bias can be minimized by eliminating the midpoint. Lastly, like in any cross-sectional study, reverse causality cannot be excluded, and associations must be interpreted with caution.

This study has several strengths. Most similar studies have examined aspects of lifestyle in isolation, such as diet/nutrition, restorative sleep, or stress, whereas the simultaneous assessment of more than three habits is scarce. Our study is among the first to evaluate the lifestyles of university students from a multidimensional approach. Moreover, most previous research has focused on the first months of the pandemic, during home confinement. The evaluation of healthy lifestyle eight to nine months after the lockdown in Spain allows us to better understand the long-term effects of the pandemic. Finally, to our knowledge, this report is the first to include not only a comparison group but also age and sex-matched participants to analyze the lifestyles of undergraduate students during the current pandemic. This design allows establishing whether the observed changes are specific to that population group or are more generic. The importance of taking into account confounding variables, such as anxiety or having experienced financial difficulties during the pandemic, should be emphasized in order to better understand the likely complex pattern of lifestyle determinants and to obtain more valuable and accurate information on lifestyle changes in undergraduate students.

\section{Conclusions}

The present study showed that participants had remarkable changes in lifestyle several months after the onset of the COVID-19 pandemic in Spain. A series of demographic and clinical variables were found to be independently associated with lifestyle during the study period. Consequently, more attention should be paid to changes in lifestyle behaviors of the young adult population during health crises, such as the current pandemic, in search of protective factors and markers of resilience. The results of this and future studies can be used to refine the public health recommendations issued to maintain or adopt healthier lifestyles.

Author Contributions: Conceptualization and methodology, V.B.-M., F.K., and R.B.D.B.; software, B.A.-C.; formal analysis, B.A.-C., A.P.-M., and R.B.D.B.; investigation, M.G.-M., B.A.-C., J.C.-M., T.B.B., B.C.-F., C.E., M.P.G.-P., S.G.-d.-C., A.G.-P., M.J.J.-M., F.S., E.V., I.Z., and R.T.-S.; writing-original draft preparation, M.G.-M., J.C.-M., B.A.-C., V.B.-M.; writing-review and editing, T.B.-B., B.C.-F., R.B.D.B., C.E., M.P.G.-P., S.G.-d.-C., A.G.-P., M.J.J.-M., F.K., F.S., E.V., I.Z., and R.T.-S.; supervision, V.B.-M. All authors have read and agreed to the published version of the manuscript.

Funding: This research received no external funding.

Institutional Review Board Statement: The study was conducted according to the guidelines of the Declaration of Helsinki, and approved by the Ethics Committee of the Hospital Universitari i Politècnic La Fe, in Valencia, Spain (2020-149-1; 26 October 2020).

Informed Consent Statement: Informed consent was obtained from all subjects involved in the study.

Acknowledgments: V.B.-M. acknowledges the national grant PI16/01770 from the Instituto de Salud Carlos III, ISCIII (The PROBILIFE study). RBDB is grateful for long-term funding from the Fundação de Amparo à Pesquisa do Estado do Rio de Janeiro (FAPERJ) (E-26/203.154/2017) and the Conselho Nacional de Desenvolvimento Científico e Tecnológico (CNPq) (312543/2020-4). EV 
thanks the support of the Spanish Ministry of Science and Innovation (PI15/00283, PI18/00805) integrated into the Plan Nacional de I + D + I and co-financed by the ISCIII-Subdirección General de Evaluación and the Fondo Europeo de Desarrollo Regional (FEDER); the Instituto de Salud Carlos III; the CIBER of Mental Health (CIBERSAM); the Secretaria d'Universitats i Recerca del Departament d'Economia i Coneixement (2017 SGR 1365), the CERCA Programme, and the Departament de Salut de la Generalitat de Catalunya for the PERIS grant SLT006/17/00357. F.K. acknowledges the grants from the Instituto Nacional de Ciência e Tecnologia Translacional em Medicina (Fundação de Amparo à Pesquisa do Estado de São Paulo [\# 2014/50891-1] and Conselho Nacional de Desenvolvimento Científico e Tecnológico [\# 465458/2014-9]), Fundação de Amparo à Pesquisa do Estado do Rio Grande do Sul (\#2012551 -0000250.0), the Canada Foundation for Innovation, the Social Sciences and Humanities Research Council, the Canadian Institutes of Health Research, and the Natural Sciences and Engineering Research Council. The authors express their gratitude to all individuals who participated in this study and to the anonymous referees, whose comments helped to improve the quality of the paper.

Conflicts of Interest: V.B.-M. has received grants and served as consultant, advisor or continuing medical education (CME) speaker during the last five years for the following entities: Angelini Spain, Angelini Portugal, Bristol-Myers-Squibb, Ferrer, Janssen, Juste, Lundbeck, Nutrición Médica, and Otsuka. JC-M has received grants and served as continuing medical education (CME) speaker during the last five years for Otsuka. E.V. has received grants and served as consultant, advisor or CME speaker for the following entities (unrelated to the present work): AB-Biotics, Abbott, Allergan, Angelini, Celon, Dainippon Sumitomo Pharma, Ferrer, Gedeon Richter, GH Research. Janssen, Lundbeck, Otsuka, Sage, Sanofi-Aventis, and Takeda. S.G.-d.C. has received CME-related honoraria, or consulting fees from Janssen-Cilag, Italfarmaco, Angelini and Lundbeck and reports no financial or other relationship relevant to the subject of this article. A.G.-P. has received grants and served as consultant, advisor or CME speaker for the following entities: Janssen-Cilag, Lundbeck, Otsuka, Pfizer, Sanofi-Aventis, Alter, Angelini, Exeltis, Takeda, the Spanish Ministry of Science and Innovation (CIBERSAM), the Ministry of Science (Carlos III Institute), the Basque Government, and the European Framework Program of Research. CE has received grants and served as consultant, advisor or CME speaker during the last five years for the following entities: Janssen-Cilag, Lundbeck, Otsuka and Casen Recordati. B.C.-F. has received unrestricted research funding from Instituto de Salud Carlos III, MINECO, Gobierno de Cantabria, Centro de Investigación Biomédica en Red de Salud Mental (CIBERSAM), from the 7th European Union Framework Program and Lundbeck. He has also received honoraria for his participation as a consultant and/or as a speaker at educational events from ADAMED, Mylan, Angelini, Janssen Johnson and Johnson, Lundbeck, and Otsuka Pharmaceuticals. IZ has received grants and served as consultant, advisor or CME speaker for the following entities: Janssen-Cilag, Lundbeck, Otsuka, Angelini, Takeda. F.K. reports personal fees as a speaker/consultant from Janssen-Johnson \& Johnson and from the Forum sos Young Minds. The remaining authors have no conflicts to declare. The funders had no role in the design of the study; in the collection, analyses, or interpretation of data; in the writing of the manuscript; or in the decision to publish the results.

\section{References}

1. Balanzá-Martínez, V.; Atienza-Carbonell, B.; Kapczinski, F.; de Boni, R.B. Lifestyle Behaviours during the COVID-19-Time to Connect. Acta Psychiatr. Scand. 2020, 141, 399-400. [CrossRef]

2. Blom, V.; Lönn, A.; Ekblom, B.; Kallings, L.V.; Väisänen, D.; Hemmingsson, E.; Andersson, G.; Wallin, P.; Stenling, A.; Ekblom, Ö.; et al. Lifestyle Habits and Mental Health in Light of the Two Covid-19 Pandemic Waves in Sweden, 2020. Int. J. Environ. Res. Public Health 2021, 18, 3313. [CrossRef]

3. European Lifestyle Medicine Organization. What Is Lifestyle Medicine?-The European Lifestyle Medicine Organization. Available online: https:/ / www.eulm.org/what-is-lifestyle-medicine (accessed on 3 May 2021).

4. Stanaway, J.D.; Afshin, A.; Gakidou, E.; Lim, S.S.; Abate, D.; Abate, K.H.; Abbafati, C.; Abbasi, N.; Abbastabar, H.; AbdAllah, F.; et al. Global, Regional, and National Comparative Risk Assessment of 84 Behavioural, Environmental and Occupational, and Metabolic Risks or Clusters of Risks for 195 Countries and Territories, 1990-2017: A Systematic Analysis for the Global Burden of Disease Study 2017. Lancet 2018, 392, 1923-1994. [CrossRef]

5. Nyberg, S.T.; Singh-Manoux, A.; Pentti, J.; Madsen, I.E.H.; Sabia, S.; Alfredsson, L.; Bjorner, J.B.; Borritz, M.; Burr, H.; Goldberg, M.; et al. Association of Healthy Lifestyle with Years Lived without Major Chronic Diseases. JAMA Intern. Med. 2020, 180, 760-768. [CrossRef] [PubMed] 
6. $\quad$ Firth, J.; Siddiqi, N.; Koyanagi, A.; Siskind, D.; Rosenbaum, S.; Galletly, C.; Allan, S.; Caneo, C.; Carney, R.; Carvalho, A.F.; et al. The Lancet Psychiatry Commission: A Blueprint for Protecting Physical Health in People with Mental Illness. Lancet Psychiatry 2019, 6, 675-712. [CrossRef]

7. Banks, S.; Dinges, D.F. Behavioral and Physiological Consequences of Sleep Restriction. J. Clin. Sleep Med. 2007, 3, 519-528. [CrossRef]

8. Sánchez-Ojeda, M.A.; de Luna-Bertos, E.; De, E.; Bertos, L. Hábitos de Vida Saludable En La Población Universitaria. Nutr. Hosp. 2015, 31, 1910-1919. [CrossRef] [PubMed]

9. Gallè, F.; Veshi, A.; Sabella, E.A.; Çitozi, M.; da Molin, G.; Ferracuti, S.; Liguori, G.; Orsi, G.B.; Napoli, C.; Napoli, C. Awareness and Behaviors Regarding COVID-19 among Albanian Undergraduates. Behav. Sci. 2021, 11, 45. [CrossRef] [PubMed]

10. Goweda, R.A.; Hassan-Hussein, A.; Alqahtani, M.A.; Janaini, M.M.; Alzahrani, A.H.; Sindy, B.M.; Alharbi, M.M.; Kalantan, S.A. Prevalence of Sleep Disorders among Medical Students of Umm Al-Qura University, Makkah, Kingdom of Saudi Arabia. J. Public Health Res. 2020, 9, 45-49. [CrossRef]

11. Savage, M.J.; Hennis, P.J.; Magistro, D.; Donaldson, J.; Healy, L.C.; James, R.M. Nine Months into the COVID-19 Pandemic: A Longitudinal Study Showing Mental Health and Movement Behaviours Are Impaired in UK Students. Int. J. Environ. Res. Public Health 2021, 18, 2930. [CrossRef] [PubMed]

12. Gallè, F.; Sabella, E.A.; Ferracuti, S.; de Giglio, O.; Caggiano, G.; Protano, C.; Valeriani, F.; Parisi, E.A.; Valerio, G.; Liguori, G.; et al. Sedentary Behaviors and Physical Activity of Italian Undergraduate Students during Lockdown at the Time of CoViD-19 Pandemic. Int. J. Environ. Res. Public Health 2020, 17, 6171. [CrossRef] [PubMed]

13. Rodríguez-Larrad, A.; Mañas, A.; Labayen, I.; González-Gross, M.; Espin, A.; Aznar, S.; Serrano-Sánchez, J.A.; Vera-Garcia, F.J.; González-Lamuño, D.; Ara, I.; et al. Impact of COVID-19 Confinement on Physical Activity and Sedentary Behaviour in Spanish University Students: Role of Gender. Int. J. Environ. Res. Public Health 2021, 18, 369. [CrossRef]

14. Powell, P.K.; Lawler, S.; Durham, J.; Cullerton, K. The Food Choices of US University Students during COVID-19. Appetite 2021, 161, 105130. [CrossRef]

15. Dragun, R.; Veček, N.N.; Marendić, M.; Pribisalić, A.; Đivić, G.; Cena, H.; Polašek, O.; Kolčić, I. Have Lifestyle Habits and Psychological Well-Being Changed among Adolescents and Medical Students Due to COVID-19 Lockdown in Croatia? Nutrients 2020, 13, 97. [CrossRef]

16. Busse, H.; Buck, C.; Stock, C.; Zeeb, H.; Pischke, C.R.; Fialho, P.M.M.; Wendt, C.; Helmer, S.M. Engagement in Health Risk Behaviours before and during the COVID-19 Pandemic in German University Students: Results of a Cross-Sectional Study. Int. J. Environ. Res. Public Health 2021, 18, 1410. [CrossRef] [PubMed]

17. Zhao, Y.; Jiang, Z.; Guo, S.; Wu, P.; Lu, Q.; Xu, Y.; Liu, L.; Su, S.; Shi, L.; Que, J.; et al. Association of Symptoms of Attention Deficit and Hyperactivity with Problematic Internet Use among University Students in Wuhan, China During the COVID-19 Pandemic. J. Affect. Disord. 2021, 286, 220-227. [CrossRef] [PubMed]

18. Gallego-Gómez, J.I.; Campillo-Cano, M.; Carrión-Martínez, A.; Balanza, S.; Rodríguez-González-Moro, M.T.; Simonelli-Muñoz, A.J.; Rivera-Caravaca, J.M. The COVID-19 Pandemic and Its Impact on Homebound Nursing Students. Int. J. Environ. Res. Public Health 2020, 17, 7383. [CrossRef]

19. Vieta, E.; Pérez, V.; Arango, C. Psychiatry in the aftermath of COVID-19. Rev. Psiquiatr. Salud. Ment. 2020, 13, 105-110. [CrossRef] [PubMed]

20. Aylie, N.S.; Mekonen, M.A.; Mekuria, R.M. The Psychological Impacts of COVID-19 Pandemic among University Students in Bench-Sheko Zone, South-West Ethiopia: A Community-Based Cross-Sectional Study. Psychol. Res. Behav. Manag. 2020, 13, 813-821. [CrossRef]

21. Balanzá-Martínez, V.; Kapczinski, F.; de Azevedo Cardoso, T.; Atienza-Carbonell, B.; Rosa, A.R.; Mota, J.C.; de Boni, R.B. The Assessment of Lifestyle Changes during the COVID-19 Pandemic Using a Multidimensional Scale. Revista de Psiquiatria $y$ Salud Mental 2021, 14, 16-26. [CrossRef]

22. De Boni, R.B.; Balanzá-Martínez, V.; Mota, J.C.; de Azevedo Cardoso, T.; Ballester, P.; Atienza-Carbonell, B.; Bastos, F.I.; Kapczinski, F. Depression, Anxiety, and Lifestyle among Essential Workers: A Web Survey from Brazil and Spain during the COVID-19 Pandemic. J. Med. Internet Res. 2020, 22, e22835. [CrossRef]

23. Kroenke, K.; Spitzer, R.L.; Williams, J.B.W. The Patient Health Questionnaire-2: Validity of a two-item depression screener. Med. Care 2003, 41, 1284-1292. [CrossRef]

24. Spitzer, R.; Kroenke, K.; Williams, J.B.W.; Löwe, B. A brief measure for assessing generalized anxiety disorder: The GAD-7. Arch. Intern. Med. 2006, 166, 1092-1097. [CrossRef] [PubMed]

25. Bush, K.; Kivlahan, D.R.; McDonell, M.B.; Fihn, S.D.; Bradley, K.A. The AUDIT alcohol consumption questions (AUDIT-C): An effective brief screening test for problem drinking. Ambulatory Care Quality Improvement Project (ACQUIP). Alcohol Use Disorders Identification Test. Arch. Intern. Med. 1998, 158, 1789-1795. [CrossRef] [PubMed]

26. Yamashita, T.; Kunkel, S.R. An International Comparison of the Association among Literacy, Education, and Health across the United States, Canada, Switzerland, Italy, Norway, and Bermuda: Implications for Health Disparities. J. Health Commun. 2015, 20, 406-415. [CrossRef] [PubMed]

27. Van Duong, T.; Pham, K.M.; Do, B.N.; Kim, G.B.; Dam, H.T.B.; Le, V.-T.T.; Nguyen, T.T.P.; Nguyen, H.T.; Nguyen, T.T.; Le, T.T.; et al. Digital Healthy Diet Literacy and Self-Perceived Eating Behavior Change during COVID-19 Pandemic among Undergraduate Nursing and Medical Students: A Rapid Online Survey. Int. J. Environ. Res. Public Health 2020, 17, 7185. [CrossRef] 
28. Crespo-Facorro, B. Mental Health and the SARS-CoV-2 Pandemic. Revista de Psiquiatría y Salud Mental 2020, 13, 55-56. [CrossRef] [PubMed]

29. García-Álvarez, L.; de la Fuente-Tomás, L.; García-Portilla, M.P.; Sáiz, P.A.; Lacasa, C.M.; Santo, F.D.; González-Blanco, L.; Bobes-Bascarán, M.T.; García, M.V.; Vázquez, C.Á.; et al. Early Psychological Impact of the 2019 Coronavirus Disease (COVID-19) Pandemic and Lockdown in a Large Spanish Sample. J. Glob. Health 2020, 10, 1-15. [CrossRef]

30. Lasheras, I.; Gracia-García, P.; Lipnicki, D.M.; Bueno-Notivol, J.; López-Antón, R.; de la Cámara, C.; Lobo, A.; Santabárbara, J. Prevalence of Anxiety in Medical Students during the Covid-19 Pandemic: A Rapid Systematic Review with Meta-Analysis. Int. J. Environ. Res. Public Health 2020, 17, 6603. [CrossRef]

31. Auerbach, R.P.; Mortier, P.; Bruffaerts, R.; Alonso, J.; Benjet, C.; Cuijpers, P.; Demyttenaere, K.; Ebert, D.D.; Green, J.G.; Hasking, P.; et al. WHO World Mental Health Surveys International College Student Project: Prevalence and Distribution of Mental Disorders. J. Abnorm. Psychol. 2018, 127, 623-638. [CrossRef]

32. Romero-Blanco, C.; Rodríguez-Almagro, J.; Onieva-Zafra, M.D.; Parra-Fernández, M.L.; Prado-Laguna, M.C.; HernándezMartínez, A. Physical Activity and Sedentary Lifestyle in University Students: Changes during Confinement Due to the COVID-19 Pandemic. Int. J. Environ. Res. Public Health 2020, 17, 6567. [CrossRef]

33. Coyle, C.; Ghazi, H.; Georgiou, I. The Mental Health and Well-Being Benefits of Exercise during the COVID-19 Pandemic: A Cross-Sectional Study of Medical Students and Newly Qualified Doctors in the UK. Ir. J. Med. Sci. 2020, 1-2. [CrossRef]

34. El-Monshed, A.H.; El-Adl, A.A.; Ali, A.S.; Loutfy, A. University Students under Lockdown, the Psychosocial Effects and Coping Strategies during COVID-19 Pandemic: A Cross Sectional Study in Egypt. J. Am. Coll. Health 2021, 1-12. [CrossRef] [PubMed]

35. Brouwer, K.R.; Walmsley, L.A.; Parrish, E.M.; McCubbin, A.K.; Braido, C.E.C.; Okoli, C.T.C. Examining the Associations between Self-Care Practices and Psychological Distress among Nursing Students during the COVID-19 Pandemic. Nurse Educ. Today 2021, 100. [CrossRef] [PubMed]

36. Flaudias, V.; Zerhouni, O.; Pereira, B.; Cherpitel, C.J.; Boudesseul, J.; de Chazeron, I.; Romo, L.; Guillaume, S.; Samalin, L.; Cabe, J.; et al. The Early Impact of the COVID-19 Lockdown on Stress and Addictive Behaviors in an Alcohol-Consuming Student Population in France. Front. Psychiatry 2021, 12, 628631. [CrossRef] [PubMed]

37. Browning, M.H.E.M.; Larson, L.R.; Sharaievska, I.; Rigolon, A.; McAnirlin, O.; Mullenbach, L.; Cloutier, S.; Vu, T.M.; Thomsen, J.; Reigner, N.; et al. Psychological Impacts from COVID-19 among University Students: Risk Factors across Seven States in the United States. PLoS ONE 2021, 16, e0245327. [CrossRef] [PubMed]

38. Sun, S.; Goldberg, S.B.; Lin, D.; Qiao, S.; Operario, D. Psychiatric Symptoms, Risk, and Protective Factors among University Students in Quarantine during the COVID-19 Pandemic in China. Glob. Health 2021, 17, 15. [CrossRef] [PubMed]

39. White, H.R.; Stevens, A.K.; Hayes, K.; Jackson, K.M. Changes in Alcohol Consumption among College Students Due to Covid-19: Effects of Campus Closure and Residential Change. J. Stud. Alcohol Drugs 2020, 81, 725-730. [CrossRef] [PubMed]

40. Galasso, V.; Pons, V.; Profeta, P.; Becher, M.; Brouard, S.; Foucault, M. Gender Differences in COVID-19 Attitudes and Behavior: Panel Evidence from Eight Countries. Proc. Natl. Acad. Sci. USA 2020, 117, 27285-27291. [CrossRef]

41. Guzek, D.; Skolmowska, D.; Głabska, D. Analysis of Gender-Dependent Personal Protective Behaviors in a National Sample: Polish Adolescents' Covid-19 Experience (Place-19) Study. Int. J. Environ. Res. Public Health 2020, 17, 5770. [CrossRef]

42. Prowse, R.; Sherratt, F.; Abizaid, A.; Gabrys, R.L.; Hellemans, K.G.C.; Patterson, Z.R.; McQuaid, R.J. Coping With the COVID-19 Pandemic: Examining Gender Differences in Stress and Mental Health Among University Students. Front. Psychiatry 2021, 12, 650759. [CrossRef]

43. Saguem, B.N.; Nakhli, J.; Romdhane, I.; Nasr, S.B. Predictors of Sleep Quality in Medical Students during COVID-19 Confinement. L'Encéphale 2021. [CrossRef]

44. Villani, L.; Pastorino, R.; Molinari, E.; Anelli, F.; Ricciardi, W.; Graffigna, G.; Boccia, S. Impact of the COVID-19 Pandemic on Psychological Well-Being of Students in an Italian University: A Web-Based Cross-Sectional Survey. Glob. Health 2021, 17, 39. [CrossRef] [PubMed]

45. Yadav, R.K.; Baral, S.; Khatri, E.; Pandey, S.; Pandeya, P.; Neupane, R.; Yadav, D.K.; Marahatta, S.B.; Kaphle, H.P.; Poudyal, J.K.; et al. Anxiety and Depression Among Health Sciences Students in Home Quarantine During the COVID-19 Pandemic in Selected Provinces of Nepal. Front. Public Health 2021, 9, 580561. [CrossRef] [PubMed]

46. Fornili, M.; Petri, D.; Berrocal, C.; Fiorentino, G.; Ricceri, F.; Macciotta, A.; Bruno, A.; Farinella, D.; Baccini, M.; Severi, G.; et al. Psychological Distress in the Academic Population and Its Association with Socio-Demographic and Lifestyle Characteristics during COVID-19 Pandemic Lockdown: Results from a Large Multicenter Italian Study. PLoS ONE 2021, 16, e0248370. [CrossRef] [PubMed]

47. Aslan, I.; Ochnik, D.; Çınar, O. Exploring Perceived Stress among Students in Turkey during the COVID-19 Pandemic. Int. J. Environ. Res. Public Health 2020, 17, 8961. [CrossRef]

48. Firth, J.; Ward, P.B.; Stubbs, B. Editorial: Lifestyle Psychiatry. Front. Psychiatry 2019, 10, 597. [CrossRef]

49. Scotta, A.V.; Cortez, M.V.; Miranda, A.R. Insomnia Is Associated with Worry, Cognitive Avoidance and Low Academic Engagement in Argentinian University Students during the COVID-19 Social Isolation. Psychol. Health Med. 2020, 1-16. [CrossRef]

50. Micheletti Cremasco, M.; Mulasso, A.; Moroni, A.; Testa, A.; Degan, R.; Rainoldi, A.; Rabaglietti, E. Relation among Perceived Weight Change, Sedentary Activities and Sleep Quality during COVID-19 Lockdown: A Study in an Academic Community in Northern Italy. Int. J. Environ. Res. Public Health 2021, 18, 2943. [CrossRef] 
51. Subdirección General de Actividad Universitaria Investigadora de la Secretaría General de Universidades. Datos y Cifras Del Sistema Universitario Español. Publicación 2020-2021. 2021. Available online: https:/ /www.universidades.gob.es/stfls/ universidades/Estadisticas/ficheros/Datos_y_Cifras_2020-21.pdf (accessed on 18 July 2021).

52. Instituto Nacional de Estadística (National Statistics Institute). Población Residente Por Fecha, Sexo y Edad. Available online: https: / / www.ine.es/dynt3/inebase/es/index.htm?padre=1894\&capsel=1895 (accessed on 18 July 2021).

53. Instituto Nacional de Evaluación Educativa. Panorama de la Educación Indicadores de la OCDE 2019; Ministerio de Educación y Formación Profesional: Madrid, Spain, 2019.

54. Dawes, J. Do data characteristics change according to the number of scale points used? An experiment using 5-point, 7-point and 10-point scales. Int. J. Mark. Res. 2008, 50, 61-104. [CrossRef]

55. Nadler, J.T.; Weston, R.; Voyles, E.C. Stuck in the Middle: The Use and Interpretation of Mid-Points in Items on Questionnaires. J. Gen. Psychol. 2015, 142, 71-89. [CrossRef] [PubMed]

56. Garland, R. The Mid-Point on a Rating Scale: Is It Desirable? Mark. Bull. 1991, 2, 66-70. 